\title{
FURTHER STEPS IN APPLICATION OF BIM FOR BUDGETS OF TRANSPORTATION CONSTRUCTIONS
}

\author{
Stanislav Vitasek \\ Czech Technical University in Prague, Czech Republic \\ stanisla.vitasek@fsv.cvut.cz
}

\begin{abstract}
The article focuses on new attitudes, which may create a shift in calculating budgets for transportation constructions. New attitudes rely on the use of Building Information Modeling (BIM). Current schemes of work have reached its limits and nowadays, it is necessary to define further steps leading towards a full match of BIM data to budget items. The author sees opportunities in defining graphic standards to be linked to construction shapes (realistic images of constructions as elements in BIM lead to generating accurate quantities for takeoff), as well as individual construction elements (an element in BIM relates 1:1 to a budget item). In the foreseeable future, it is possible to add classification codes of elements so that element parameters make it possible to match every single element to a budget item. This would link BIM model data directly to the budget of the construction project. The last of the author's suggestions is to implement itemization of elements and include a larger scope of aggregation in the project's budget. Itemized elements serve to match so-called carry items (such elements that may be linked to BIM model with ratio 1:1) to additional tie-in items. which are not commonly included in BIM models (e.g. formwork, reinforcement, etc.). This should simplify the import of data to software which calculates the budget of the project. The process focuses on aggregation of items to fit local price systems and budget calculation practices. Larger scope of aggregation enables us to reach 1:1 ratio of the model and its budget to a greater extent. The suggested shift in attitude has been tested on two transportation construction projects namely, finishing of D1, the key motorway of the Czech Republic, and D4 motorway (also in the Czech Republic). Both of these projects have been carried out with BIM models. The goal is to summarize the total costs, which can be calculated by using BIM. BIM models are used in the same ways as the local market uses them. From this calculation, recommendations can be made.
\end{abstract}

Keywords: construction budget, graphic model, construction element, budget item, matching model to budget.

\section{Introduction}

It is our primary goal to use the highest possible degree of automated budget calculation when connecting Building Information Modeling (BIM) and a budget of a project for transportation infrastructure. Therefore, we need to establish a link between BIM model elements and individual budget items. There already exists a link given by identifying, localizing and visualizing the element both in the BIM model and the budget of project. However, the goal of best possible automation has not yet been reached in transportation infrastructure projects. Over the years of digitalization, construction businesses have become familiar with the basic scheme for using BIM data in budget calculations (which we describe further in the chapter Current use of information model for budget calculation). However, the current practice does not make full use of BIM potential. Semi-automated transfer has been adopted to use the data from BIM model for a budget calculation. This basic practice needs to be expanded to use the latest findings and make the desired progress.

This paper describes several concrete steps, which need to be made for the sake of a higher automation of the data transfer. These key steps have several cornerstones:

- research of available sources (scientific articles, professional publications, etc.) connected with cost management digitalization,

- analyses of carry constructions from actual construction projects (based on ten roadwork constructions in 2017-2019),

- data analyses of BIM models, which have been used in transportation constructions in the Czech Republic (motorways D1 and D4),

- author's practice as the Head of Development and digitalization of Cost management in an international construction company.

The suggested solutions ("shift in attitude") are generic guidelines, which may be applied in any given market background. However, when implementing the suggested guidelines for a specific construction project, the local budget calculation practices need to be taken into account. 


\section{Literature review}

Building Information Modeling and its benefits in construction business have been dealt with in scientific publications both in universities and construction practice. Professionals focus their attention on the general benefits of using information models for predicting construction's life cycle, on the necessary attention in the design phase, which may largely influence the future operational and maintenance costs $[1 ; 2]$. However, linking of BIM models to calculations of budget, or even cost management as a whole, has been slightly under-discussed so far.

Research in specialized literature focuses on publications tied to local (national) specifics in socalled BIM 5D. „Analysis of the First Polish BIM-Based Cost Estimation Application” written by Polish authors from the Cracow University of Technology and from the University of Maryland deals with the possibility to link the data from any BIM model to construction production budgets [3]. The authors analyse the realistic potential of using a local price system to tackle the data generated for BIM model elements. Their conclusions point out an insufficient data relay between a BIM model and the local price system, which had been established in the past century.

A comparable conclusion has been made by authors from the Tsinghua University, Ma and Liu in their article „BIM-based Intelligent Acquisition of Construction Information for Cost Estimation of Building Projects"[4].

In the Czech Republic, the situation is quite similar - Classification of Engineering Structures and Price System of Engineering Structures, which are currently being used for classification and budget calculation, had both been established in the 1960s. If BIM models are to be used up to their full potential, the local practices need to be modified in order to ensure a smooth transfer of the data from a BIM model to price system items.

Another publication dealing with the use of BIM in a local practice has been explored - „Study on BIM utilization for design improvement of infrastructure project" by the Tokyo City University scientists, Minagawa a Kusayanagi. This study focuses on infrastructure project designs for designbid-build contracts. The authors prove both economic and technical benefits of using BIM in different phases of a project life cycle for this type of contract [5].

The Czech practice allows for this type of contract mainly in the public sector. Unfortunately, there has been no connection made to modern technologies yet. The public sector needs to learn the essential know-how and clearly identify the level of application of BIM before implementing the full scope of BIM, and requiring its usage not only in construction projects (we suggest, e.g. international consultants or small-scale pioneer projects).

The Finnish article „The effects of BIM and lean construction on design management practice” has been written by a collective of scientific professionals and construction practice professionals. This article focuses on an identification of problems that may be caused by implementing BIM for a project management. The authors identify the key factor of successful functioning to be knowledgeability and qualification of the whole project team [6]. Finland, just like other states where BIM has been developing in construction companies, suffers from a lack of experience with the new method, as well as a limited number of available specialists. Such a lack brings an unacceptable risk for construction companies, thus limiting the potential for use of BIM in construction projects. The Czech Technical University in Prague (CTU) decided to react to the lack of available professionals by establishing a new field of studies - BIM coordinator.

\section{Current use of information model for budget calculation}

Chapter Current use of information model for budget calculation presents the current state of data utilisation in construction companies, which have already adopted BIM in the work processes. The situation is shown in Fig. 1.

Assignment specifications for a BIM designer (so-called BIM Execution Plan or BEP) usually do not define any kind of link to the calculation of budget. Mostly, BEP defines graphical and technical element specifications. When a BIM model is designed, parameters (description, volume, area, etc.) of individual elements are exported to a spreadsheet processor (or the entire model is exported to a BIM project viewer). Adjustments are made on the exported data to fit the structure of a chosen price system (local itemization of budget), then the data are imported to a budget calculating software. This 
software creates a full-fledged budget of the project, using both adjusted data and data on other construction works and items, which are not part of the design (e.g. temporary constructions, such as formwork, scaffolding, etc.) [7].

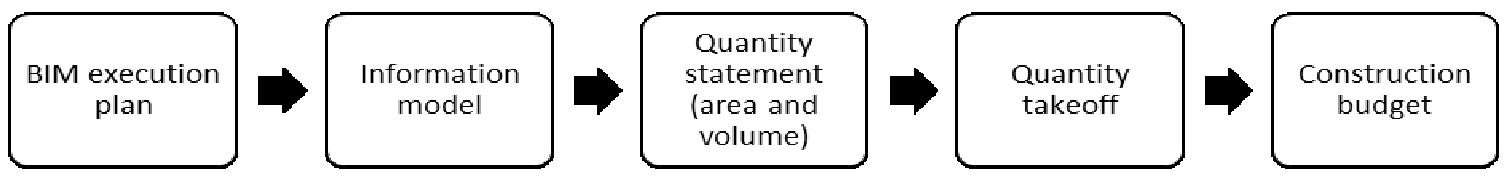

Fig. 1. Scheme of processing BIM model data for budget calculation [7]

The process, as stated above, contains a number of manual operations, which lengthen the processing of budget calculation. Automated solutions are lacking for transfer of data between software solutions. There is a need to establish a direct link between model elements and budget items.

\section{Further steps in BIM usage when calculating a budget of a project}

The potential for progress, such as using BIM for a budget calculation, is tied in with new standards, more closely oriented towards budget calculations. The author wants to state four basic rules:

- defining BIM Execution Plan with regard to budget calculation,

- using such classification system of elements, which links them directly to price items,

- implementing itemized breakdown - each element may be made up of several price items,

- applying larger scale of aggregation in construction budget.

The former two rules focus on graphical and non-graphical requirements (classification system), and are related to the BIM model as such - i.e. how the model needs to be designed in order to ensure its highest efficiency when calculating the budget of project.

The latter two rules focus on follow-up work with data, when BIM model already exists and when it is used to calculate the budget of project.

\section{Graphical requirements}

Each segment of the construction market has specific data requirements. From the budget viewpoint, it is essential that each BIM model element corresponds with a real shape of construction, so that the generated quantity takeoffs correspond with reality. At the same time, it is necessary that each construction element is linked to a budget item by ratio 1:1 (i.e. one element of construction is one item of budget). BEP often refers to the Level of Development standards (LOD) because of the lack of comprehensive national standards. LOD is then supplemented by the requirements of national legal regulations specifying the scope and content of a project documentation. For budget calculations, graphical level LOD 350 is advisable for several reasons. An element in BIM is graphically demonstrated as a specific system, object or configuration with a given quantity, size, shape, orientation, and divisions. [8] In other words, an element in construction information model needs to correspond with the realistic geometry of a construction, including bends, openings, etc. Further increase of the level of detail (e.g. LOD 400) would also increase the time needed for creating a BIM model, and thus also the total cost for design would increase. Therefore, it is currently debatable whether creating detailed models is beneficial to the project, given the fact that information modeling is still a developing field of design.

Unfortunately, the Czech construction practice does not allow us to find several BIM models of the same project on different levels of graphic detail (such as LOD 200 and LOD 350). If this were possible, it would allow us to make a direct comparison of its potential for calculating a budget.

\section{Classification system}

When adding a non-graphic entry to element parameters, such as a classification system, we are able to unify code designations for elements in BIM model, and items in the budget of project. Thus we are able to program an automated pairing of elements and items for import to pricing software. 
The code of element itself, also called identifier, should unequivocally define its function, type, and characteristics, ideally with a direct link to the local pricing practice. This would ensure that the transfer of the model data to the pricing software is as smooth as possible. Matching of a BIM model element to its identifier must be carried out by the designer of the BIM model. However, this does not lead to a substitution of the estimator's work by the designer's work. This process only helps classify the elements (constructions) in a BIM model to make them suited for further work, i.e. a budget calculation. Nowadays, designers of information models have already started the practice of classifying elements. Unfortunately, this practice is not followed by using established links to budget calculations, e.g. by using the Czech classification system SNIM, Swedish Coclass or British Uniclass.

\section{Element breakdown in items}

Element breakdown is a process focusing on the transformation of element data from a BIM model to match individual budget items. The process is based on an automated matching of so-called tie-in items to so-called carry items before the import of data to pricing software. The match ratio is $1: \mathrm{N}$, where one carry item may be linked to several tie-in items. A carry item is a construction, which is depicted as an individual element in a BIM model (the ratio for such elements is 1:1 element:item). Tie-in items, on the other hand, are usually such items, which are not graphically depicted in the construction's information model.

The final operation of element breakdown in items ought to be performed only in pricing software, where the estimator needs to choose which tie-in items will be used for a budget calculation. The functionality of given program should be integrated to simplify further operations, because code identification of element in a given classification system is a key piece of information that enables the identification of carry and tie-in items.

On the grounds of the author's analysis of carry items in real transportation construction projects (mostly within the Czech Republic), we have established three major groups of carry and tie-in items, which should be a part of element breakdown in items. These are:

- composite constructions (floors, walls, roofs, etc.),

- temporary and secondary constructions (formwork, scaffolding, security structures, etc.),

- customary systems or processes for budget calculation (excess charges, transport of material, groundwork transport, etc.).

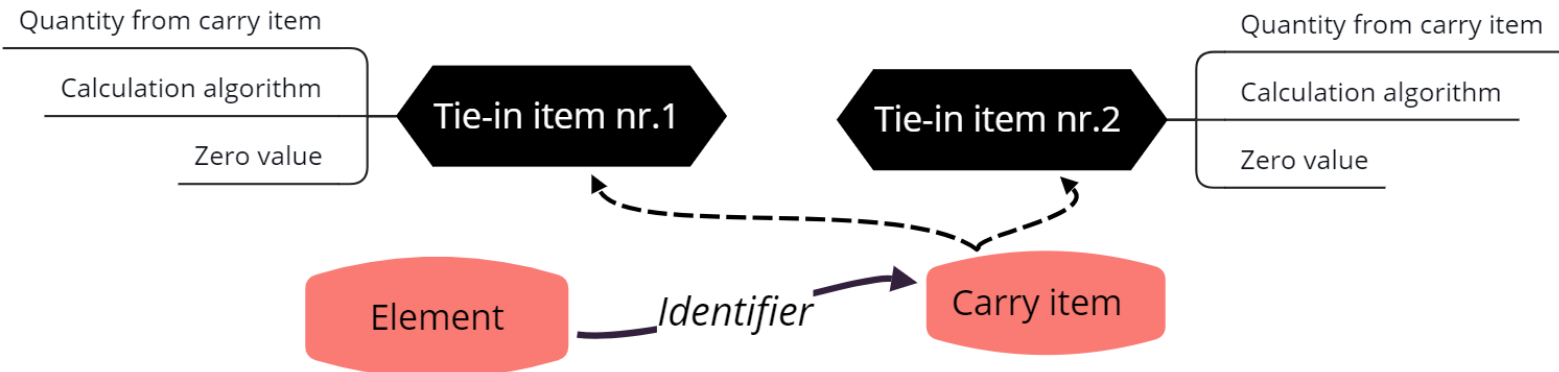

Fig. 2. Scheme of element breakdown in items with use of identifier

Quantities of carry items are generated directly from the information model of construction. Tiein items may be eventually also generated directly, or by means of an assigned algorithm, or they may be expressed as nil (graphically represented by Fig. 2). Nil value means that we are unable to establish a calculated relation between a carry and a tie-in item. In such case, manual calculations need to be carried out.

\section{Aggregation}

Aggregation is generally a process of uniting several parts to create a superordinate whole, a socalled aggregate. In construction industry, it means the consolidation of several construction items in one, where there is no need (usually by estimator's requirement) for a detailed study. In BIM models, this is applied to designers' work to ensure a depiction of elements in such manner that the ratio 1:1 (element: budget item) can be reached. Tie-in items, however, become a part of a larger whole and due to aggregation do not need graphical representations. 
In transportation infrastructure, those constructions, which require secondary works, are suggested for aggregations. Typically, those are prep works for constructions connected to groundwork, e.g. drilling for pilots (the aggregate will constitute of both drilling and pilots), slots for drainpipes including gravel (the aggregate will constitute digging of slots, drainpipe, and gravel), etc. Within the framework of the Czech construction market, both aggregates would stand for three individual budget items.

Aggregation, however, is not always the adequate solution. Especially for such constructions, where it is impossible to establish unequivocal estimates of time and material per unit. When unable to meet the requirement of unequivocality, we should prefer the element breakdown in items, as described in the preceding chapter.

\section{Case study}

A Case study has been carried out to compare budget calculations, which were done with BIM models following the standard procedures (see third chapter of this article), and budget calculations with suggested "update" - supplementing of an identifier in element parameters, itemized breakdown, and aggregation. Unfortunately, it was impossible to analyse these processes applied to higher graphical standards (which is an essential part of the author's suggestions) - in the Czech Republic, there are currently no graphically adequate models of the transportation infrastructure.

Thanks to CTU's cooperation with construction companies on maintaining the project Centre for Effective and Sustainable Transport Infrastructure (CESTI), we managed to obtain two information models of transportation infrastructure. It is in no way simple to come by BIM models, as construction companies need to secure their data "know-how". The following models are from 2017 and 2018. The graphic standard of both information models is LOD 300 [9].

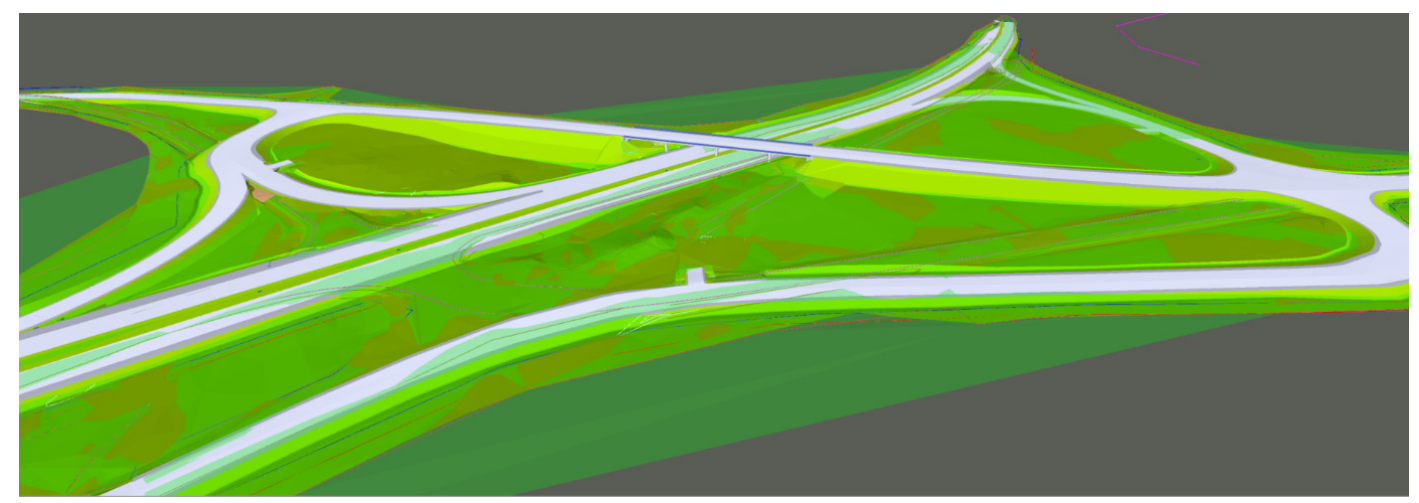

Fig. 3. Motorway D4 - Skalka in BIM

The first construction project is finishing of a five-kilometer stretch of motorway D4 - Skalka in Central Bohemian region. The second construction project is the construction of a fourteen-kilometer stretch of motorway D1 between the cities Lipník nad Bečvou and Přerov. The analysis focuses in both cases on a single type of construction element designated as Main road track [9].

Table 1

Information on construction of motorwaysD4, D1 [10]

\begin{tabular}{|c|c|c|c|c|c|}
\cline { 5 - 6 } \multicolumn{1}{c|}{} & D4 & D1 & & D4 & D1 \\
\hline $\begin{array}{c}\text { Beginning of } \\
\text { construction }\end{array}$ & $04 / 2014$ & $08 / 2015$ & $\begin{array}{c}\text { Construction's } \\
\text { opening }\end{array}$ & $09 / 2018$ & $08 / 2019$ \\
\hline Road length & $4.8 \mathrm{~km}$ & $14.3 \mathrm{~km}$ & Winning bid & $\begin{array}{c}417485 \\
287 \mathrm{CZK}\end{array}$ & $2717043775 \mathrm{CZK}$ \\
\hline Object & \multicolumn{2}{|c|}{ Main road track } & Object value & $\begin{array}{c}10238332 \\
1 \mathrm{CZK}\end{array}$ & $624072760 \mathrm{CZK}$ \\
\hline
\end{tabular}

The first part of the case study analyses information models of constructions from the viewpoint of how useful the data of the project are for a calculation of budget without any further adjustments. It was the author's goal to find out how large a percentage of budget (compared to manual calculations) we are able to obtain directly from the BIM model, i.e. how many elements really correspond to $1: 1$ 
ratio to budget items under the current Czech construction market situation. The process is shown in Fig. 4 with examples. The items highlighted in orange represent a concrete foot, which is graphically represented in the BIM model of the project. It can be matched using 1:1 ratio to a budget item, thus adding a value of CZK 1,200,350 to carry items. The items highlighted in green represent groundwork - earth furrow, which cannot be graphically represented in a BIM model. This item adds a value of CZK 810,356 to the tie-in items, which cannot be matched directly.

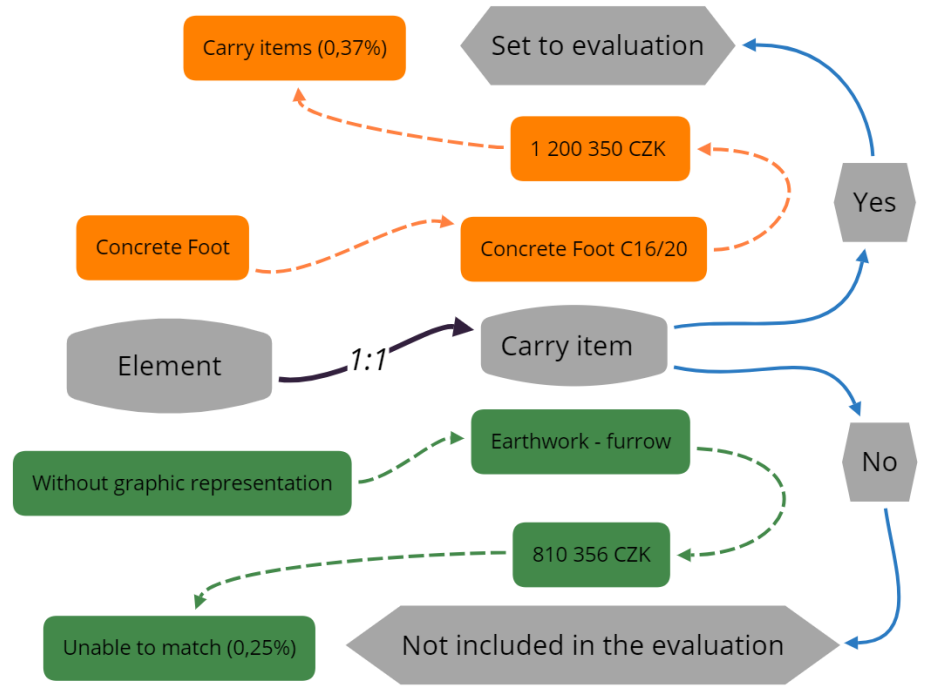

Fig. 4. Process of evaluation of BIM data for the use of budget

An analysis followed the scheme of a budget calculation depicted in Fig. 1. Both BIM models were used to export information about their elements. The function "Quantities" was used and an analysis was carried out in Revit program by Autodesk, Inc. The data were transformed in a spreadsheet processor to create a budget following the customary Czech processes. An evaluation was made of the amount of BIM data which could be used as such.

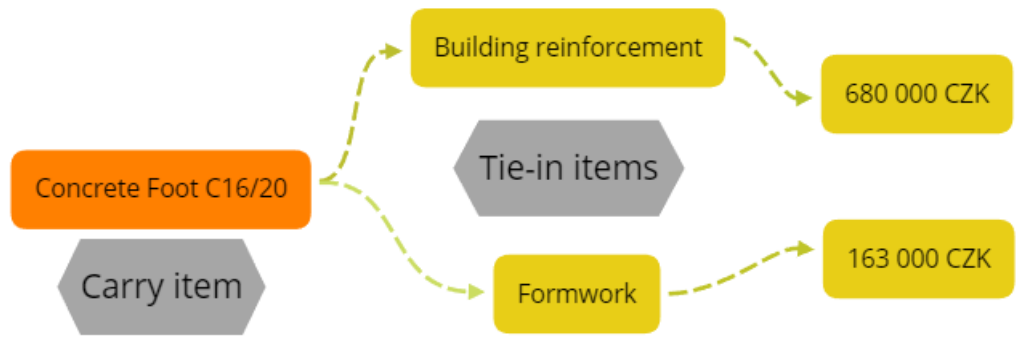

Fig. 5. The process of evaluation of tie-in items and their specification

The second part of this case study applies several chosen steps of the above suggested process to already existing BIM models. Due to their pre-existence, specific graphic demands for BIM models could not be applied. However, the non-graphic parts of models may be supplemented at any time. To execute these steps, Navisworks program by Autodesk, Inc. has been chosen. This program allows for the import of a database system to classify elements. For the sake of this study, the Czech-specific database called Price System of Engineering Structures was used. Unfortunately, some degree of manual matching of identifiers to elements was necessary. The following two steps - an element breakdown in items, and aggregation - were accomplished with the use of ASPE program by IBR Consulting, Inc., which has been developed to calculate the budgets for transportation infrastructure projects using the Price System of Engineering Structures. This part of the process was time consuming, as it was necessary to match tie-in items with carry items, and to add up items for aggregation. Fig. 5 demonstrates the process of evaluation of tie-in items for the case study based on Fig. 2. The concrete foot, which is graphically represented in the model and as such is a directly matchable carry item, is supplemented by items of the pricing system, which define the costs of reinforcement and formwork (highlighted in yellow). These tie-in items add a value of CZK 843,000 to the budget group of tie-in items. 


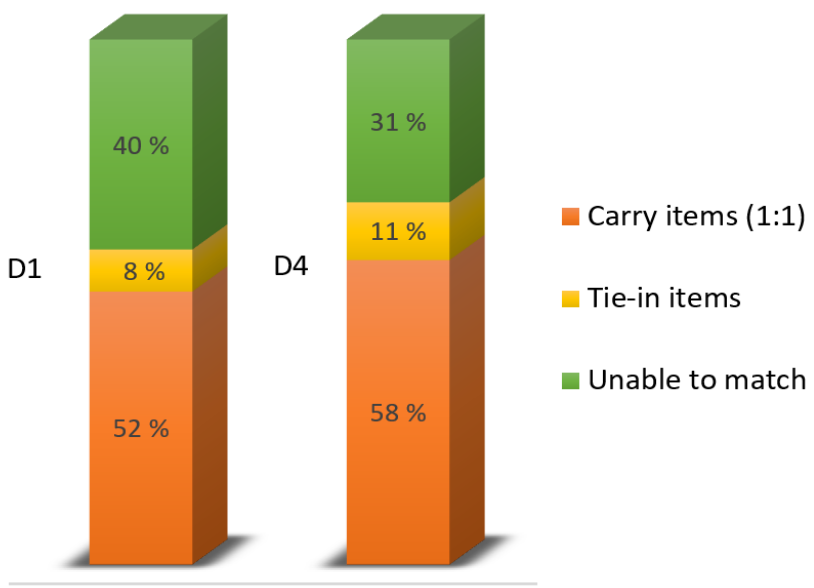

Fig. 5. Graphic evaluation of case studies

For the motorway D1 project, elements could be matched on 1:1 ratio to a total amount of 325 mil. CZK, which constitutes $52 \%$ of the summary budget for Main road track. Secondary additions (classification system, element breakdown in items, aggregation) led to a further $8 \%$ rise in the budget (which is rise by 48 mil. CZK).

The second project - motorway D4 showed somewhat better results. By combining a 1:1 ratio budget transfer with secondary steps (classification system, element breakdown in items, aggregation), we managed to reach a level of matchable items corresponding with $69 \%$ of the project budget, i.e. 71 mil. CZK (11 mil. CZK thereof is due to secondary matching). A higher level of matching could not be reached due to the insufficient graphic level of project designs.

The case study suggests the necessity of furthering the steps towards a higher matchability of elements to budget items, so that BIM becomes more efficient with regard to budget calculations.

\section{Conclusions}

BIM 5D itself requires a high-quality level information model. Detailed execution plans for the design are key element leading to a successful implementation of BIM in budget calculations concerning transportation infrastructure projects. The suggested shift in the discussed problematics follows:

1. Use of the graphic standard LOD 350 with connection to the local customs of budget creation, i.e. use of elements in 1:1 ration (element: item) and a realistic design of construction for quantity takeoff.

2. Use of a classification system for elements (SNIM, CoClass, Uniclass etc.) with a connection to the local customs of budget creation, i.e. the placement of code in the parameters of an element, which will later on be the same as code of budget item.

3. Implementation of the method of element breakdown in items for the use of data transfer from a BIM model to the budget of project, i.e. creation of a database of tie-in items in pricing software so that they are matched automatically with the carry items when calculating a budget.

4. Application of a larger amount of aggregated budget items.

5. Creation of pressure on both the public and the private organizations dealing with digitalization of construction industry so that national standards are created for all fields of construction industry.

\section{Acknowledgements}

This work was supported by the Grant Agency of the Czech Technical University in Prague, grant No. SGS20/101/OHK1/2T/11.

\section{References}

[1] Matejka P., Kosina V., Tomek A., Tomek R., Berka V., Šulc D. The Integration of BIM in Later Project Life Cycle Phases in Unprepared Environment from FM Perspective. Procedia Engineering Volume 164, 2016, stránky 550-557. DOI: 10.1016/j.proeng.2016.11.657 
[2] Marzouk M., AZAB S., METAWIE M. BIM-based approach for optimizing life cycle costs of sustainable buildings. Procedia Engineering Volume 188, 2018, Pages 217-226. DOI: 10.1016/j.jclepro.2018.03.280

[3] Plebankiewicza E., Zima K., Skibniewski M. Analysis of the First Polish BIM-Based Cost Estimation Application. Procedia Engineering Volume 123, 2015, stránky 405-414. DOI: 10.1016/j.proeng.2015.10.064

[4] Ma Z., Zhe L. BIM-based Intelligent Acquisition of Construction Information for Cost Estimation of Building Projects. Procedia Engineering Volume 85, 2014, stránky 358-367. DOI: 10.1016/j.proeng.2014.10.561

[5] Masaru M., Kusayanagi S. Study on BIM Utilization for Design Improvement of Infrastructure Project. Procedia Engineering Volume 125, 2015, stránky 431-437. DOI: 10.1016/j.proeng.2015.11.113

[6] Tauriainen M., Marttinen P., Dave B., Koskela L. The Effects of BIM and Lean Construction on Design Management Practices. Procedia Engineering Volume 164, 2016, stránky 567-574. DOI: 10.1016/j.proeng.2016.11.659

[7] Vitasek S., Zak J. Cost estimating and building information modelling (BIM) in road construction. Proceedings. Budapest: Diamond Congress Ltd., 2018. p. 403-410. ISBN 978-615-5270-45-1

[8] Bimforum: LOD specification. [online] 20.03.2020]. Available at: https://bimforum.org/wpcontent/uploads/2013/08/2013-LOD-Specification.pdf

[9] Skanska: D4 Skalka - II/118. [online] 22.03.2020]. Available at: https://www.skanska.cz/codelame/specialni-cinnosti/bim/probihajici-projekty/r4-skalka-krizovatka-ii-118/

[10] Directorate of roads and highways: Information about Skalka-II/118. [online] 24.03.2020]. Available at: http://www.dalniced4.cz/public/files/documents/infoletak-d4-skalka-s1181484154827401-2016-12.pdf 